NBER WORKING PAPER SERIES

\title{
AN EMPIRICAL EXAMINATION OF THE FISHER EFFECT IN AUSTRALIA
}

Frederic S. Mishkin

John Simon

Working Paper No. 5080

\section{NATIONAL BUREAU OF ECONOMIC RESEARCH 1050 Massachusetts Avenue \\ Cambridge, MA 02138 \\ April 1995}

We would like to thank members of Economic Group at the Reserve Bank of Australia for helpful comments. Naturally, all errors are our own. This paper is part of NBER's research programs in Economic Fluctuations and Monetary Economics. Any opinions expressed are those of the authors and not those of the Reserve Bank of Australia or the National Bureau of Economic Research.

(ㄷ 1995 by Frederic S. Mishkin and John Simon. All rights reserved. Short sections of text, not to exceed two paragraphs, may be quoted without explicit permission provided that full credit, including $(\mathcal{O}$ notice, is given to the source. 


\title{
AN EMPIRICAL EXAMINATION OF THE FISHER EFFECT IN AUSTRALIA
}

\begin{abstract}
This paper analyzes the Fisher effect in Australia. Initial testing indicates that both interest rates and inflation contain unit roots. Furthermore, there are indications that the variables have non-standard error processes. To overcome problems associated with this and derive the correct small sample distributions of test statistics we make use of Monte Carlo simulations. These tests indicate that while a long-run Fisher effect seems to exist there is no evidence of a short-run Fisher effect. This suggests that, while short-run changes in interest rates reflect changes in monetary policy, longer-run levels indicate inflationary expectations. Thus, the longer-run level of interest rates should not be used to characterize the stance of monetary policy.
\end{abstract}

Frederic S. Mishkin

Federal Reserve Bank of New York

33 Liberty Street

New York, NY 10045

and NBER
John Simon

Reserve Bank of Australia

65 Martin Place

Box 3947 GPO Sydney 2001

AUSTRALIA 


\section{AN EMPIRICAL EXAMINATION OF THE FISHER EFFECT \\ IN AUSTRALIA}

\section{Frederic S. Mishkin and John Simon}

\section{INTRODUCTION}

Does a rise in short-term interest rates reflect a rise in real interest rates and, hence, a tightening of monetary policy or, alternatively, a rise in expected inflation? A standard view, commonly referred to as the Fisher effect, is that movements in short-term interest rates primarily reflect fluctuations in expected inflation and, as such, they have predictive ability for future inflation. If this is the case a rise in short-term interest rates does not indicate a tightening of the stance of monetary policy but rather a rise in expected inflation. This would suggest a need for caution in using the level of nominal interest rates as indicators of the tightness of monetary policy.

Not surprisingly, because of its importance to policy, the relationship between the level of interest rates and future inflation has been studied in many countries. The Fisher effect has been found to be strong in some countries over certain periods, for example in the United States, Canada and the United Kingdom in the post-war period until 1979. However, the correlation between interest rates and expected inflation has not been high post-1979 or in other countries. ${ }^{1}$

These results raise the puzzle of why the Fisher effect is strong for certain countries and certain time periods but not for others. In a recent paper, Mishkin (1992) finds an answer to this puzzle for the United States. The paper finds support for a long-run Fisher relationship in which inflation and interest rates are cointegrated. The existence of a long-run Fisher effect implies that when inflation and interest rates exhibit trends, as occurred with the rise in rates in the 1970s, these two series will trend together and, thus, there will be a strong correlation between the two. As a result the Fisher effect appears to be strong in the periods when interest rates and inflation exhibit trends. On the other hand, the evidence does not support the existence of a short-run Fisher relationship in which a change in expected inflation is associated with a change in interest rates. So, when interest rates and expected 
inflation do not exhibit trends, as occurred though the 1980s when inflation and interest rates were relatively stable, a strong correlation between interest rates and inflation will not appear.

This paper uses the methodology outlined in Mishkin (1992) to analyse the strength of the Fisher effect in Australia. In particular we make use of Monte Carlo simulations to determine the true distributions of test statistics. We find no evidence for a short-run Fisher relationship although there is some evidence for a long-run Fisher relationship. This evidence suggests that changes in short-term interest rates in Australia indicate a tightening or loosening of monetary policy, whereas the longerrun level of short-term interest rates, instead of providing information on the tightness of monetary policy, reflect expectations of inflation.

\section{THE METHODOLOGY FOR TESTING THE FISHER EFFECT}

In previous work examination of the Fisher effect has involved testing for a significant correlation of the level of interest rates and future inflation: i.e., testing for the significance of $\beta$ in the following forecasting regression:

$$
\pi_{t}=\alpha+\beta i_{t}+\eta_{t}
$$

where,

$$
\begin{aligned}
& \pi_{t}=\text { the one period future inflation rate from time } t \text { to } t+1 . \\
& i_{t}=\text { the one period future interest rate known at time } t .
\end{aligned}
$$

The reason (1) can be thought of as a forecasting equation is that, while both interest rates and inflation cover the same time period, interest rates are known at the beginning of period $t$ while inflation is only known in period $t+1$. We can view the correlation of interest rates and future inflation as interesting in its own right. Alternatively, we can interpret this regression by assuming that expectations are rational as in Fama (1975). If expected inflation were observable, information on the correlation of the level of interest rates and expected inflation could be obtained by testing for the significance of the $\beta$ coefficient in the regression (2) below:

$$
E_{t}\left[\pi_{t}\right]=\alpha+\beta i_{t}+u_{t}
$$


where,

$$
E_{\mathrm{t}}[\cdot]=\text { the expectation conditional on all information available at time } t \text {. }
$$

Under rational expectations, the realised future inflation rate can be written as,

$$
\pi_{t}=E_{t}\left[\pi_{t}\right]+\varepsilon_{t}
$$

where the forecast error of inflation, $\varepsilon_{t}$, is orthogonal to any information known at time $t$ which includes $i_{t}$. Combining equations (2) and (3) results in equation (1) in which the error term, $\eta_{t}$, is equal to $\varepsilon_{t}+u_{t}$. Since $u_{t}$ is orthogonal to $i_{t}$ by construction and $\varepsilon_{t}$ is orthogonal to $i_{t}$ under rational expectations, $\eta_{t}$ is also orthogonal to $i_{t}$ and an ordinary least squares (OLS) estimate of $\beta$ in the forecasting equation (1) is a consistent estimate of $\beta$ in equation (2). Thus, given rational expectations, a test of the correlation of interest rates with future inflation is also a test for the correlation of interest rates and expected inflation.

The results from estimating equation (1) appear in Table 1 below. The estimation periods reported are; the full sample period, 1962 III to 1993 IV; 1962 III to 1979 III and 1979 IV to 1993 IV.

\begin{tabular}{|c|c|c|c|c|}
\hline Sample period & $\alpha$ & $\beta$ & $R^{2}$ & $S E$ \\
\hline 1962 III-1993 IV & $\begin{array}{c}3.33 \\
(4.52)\end{array}$ & $\begin{array}{c}0.39 \\
(5.87)\end{array}$ & 0.14 & 4.12 \\
\hline $1962 \mathrm{III}-1979 \mathrm{III}$ & $\begin{array}{l}3,21 \\
(2,58)\end{array}$ & $\begin{array}{l}175 \\
(785)\end{array}$ & 0.47 & 3.72 \\
\hline 1979 IV-1993 IV & $\begin{array}{l}-1.09 \\
(1.04)\end{array}$ & $\begin{array}{c}0.63 \\
(7.58)\end{array}$ & 0.40 & 2.75 \\
\hline
\end{tabular}

Table 1: Estimates of Inflation Forecasting Equation $\pi_{t}=\alpha+\beta i_{t}+\eta_{t}$

Note: $\mathrm{t}$-statistics in parentheses.

The sample has been split into these two sub-periods for two reasons. First, the Treasury note market was administered in such a way until 1979 III that note rates did not reflect market clearing prices on a day to day basis. With deregulation of the Treasury note market in December 1979 rates were subsequently set by the market. A secondary reason to suspect a break around that time is that previous research (for example Clarida and Friedman (1984), Huizinga and Mishkin (1984) and 
Cumby and Mishkin (1986)) indicate that with the change in US monetary policy procedures in October 1979 the stochastic process for real interest rates shifted both in the United States and abroad. $^{2}$

A graph of the data series used is presented below, further details are included in Appendix B. As can be seen and as discussed above the Treasury note rate shows a distinct break from December 1979 on as a result of financial deregulation.

Figure 1: Short-Term Interest Rate and Inflation

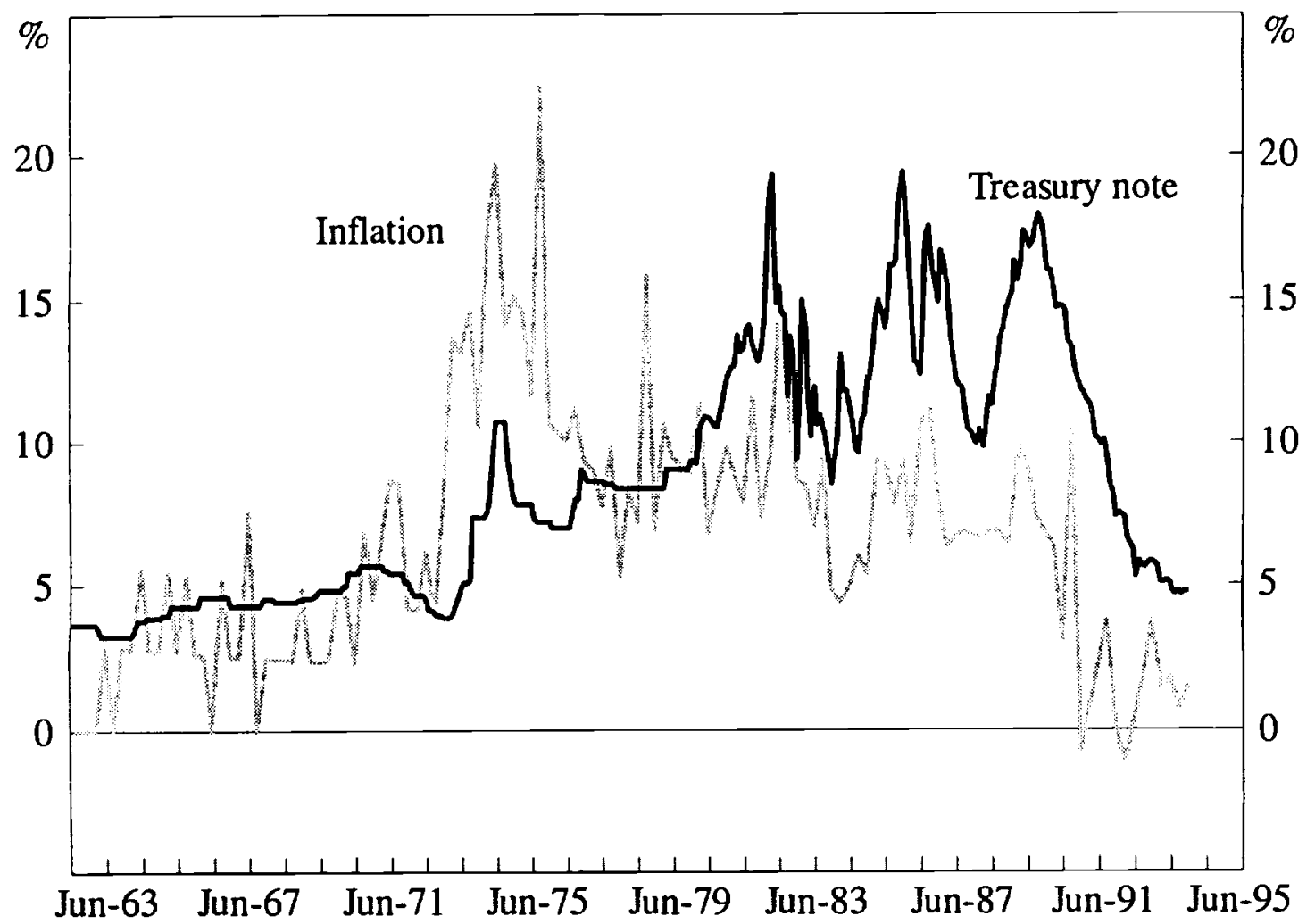

The $R^{2}$ s for the equation (1) estimates are above 0.4 for the two sub-samples and above 0.1 for the full sample. The high $t$-statistics on the $\beta$-coefficient seem to indicate that the correlation between expected inflation and nominal interest rates is statistically significant, indicating the presence of a strong Fisher effect. However, as we argue in the next subsection, the potential for unit roots in inflation and interest rate makes this evidence for a Fisher effect somewhat suspect. 


\section{II (a) The Problem of Unit Roots}

It is well known that if the variables in a regression contain stochastic trends because their time series processes have unit roots, then inference with t-distributions can be highly misleading. ${ }^{3}$ Consequently, to determine if the levels of inflation and interest rates contain stochastic trends and, thus, if more sophisticated cointegration techniques should be used to analyse equation (1), we conducted a number of unit root tests.

\section{II (a) (i) The Problem with Unit Root Test Statistics}

Before conducting the unit root tests, however, it is necessary of be aware of one more possible problem. The critical values calculated by Dickey and Fuller for standard unit root tests can be very misleading in small samples or if the time-series models of the variables tested for unit roots are not

pure autoregressive processes but rather include important moving average terms. ${ }^{4}$ The Australian inflation data suffer from this problem and, therefore, it is necessary to obtain the correct small sample distributions for these test statistics from Monte Carlo simulations which allow for more general time-series processes of the tested variables.

The Monte Carlo simulation experiments were conducted as follows. The variables $\pi_{l}$ and $i_{\text {, }}$ were assumed to be described by ARIMA models in first differenced form (i.e. assuming unit roots)..$^{5}$ The parameters for these models were estimated from the relevant sample periods. However, there was evidence to suggest that the error terms contained Auto-Regressive Conditional Heteroskedasticity $(\mathrm{ARCH})$. To capture this the ARCH process was estimated for the relevant sample periods. The error terms in the data generating process were then based upon this process rather than standard normal errors.

In generating the synthetic data for the Monte Carlo experiments a number of setup conditions were used. Initial values of the data needed for the auto-regressive (AR) component of the models were obtained from the earliest available actual data. Errors over this period were assumed to be standard normal with a variance matching the estimated variance of the actual data without allowance for ARCH. Following this the errors were modelled using the ARCH process estimated earlier. Five years of synthetic data were generated to allow both the ARCH and AR processes to stabilise. The 
data generated from then on were assigned to the period from 1962 III to 1993 IV. These data were used in the same way as the actual data, that is, estimation over sub-periods made use of the first or second half of the data as appropriate. One thousand sets of data were used to calculate the relevant test statistics.

\section{II (b) Unit Root Tests}

Table 2 below presents several types of unit root tests. The DF statistic is the DickeyFuller $(1979,1981) \mathrm{t}$-statistic, $(\hat{\rho}-1) / s(\hat{\rho})$, from the following regression:

$$
Y_{t}=k+\rho Y_{t-1}+u_{t}
$$

where $s(\hat{\rho})$ is the OLS standard error of $\hat{\rho}$ and $Y_{t}$ is the variable being tested for unit roots. The $Z_{t}$ statistic is a modification of the Dickey-Fuller t-statistic suggested by Phillips (1987) which allows for autocorrelation and conditional heteroskedasticity in the error term of the Dickey-Fuller regression. The $Z_{\alpha}$ statistic, also suggested by Phillips (1987), is a similar modification of the test statistic $T(\hat{\rho}-1)$, where $T$ is the number of observations. ${ }^{6}$

In Table 2 the value in parentheses under the test statistic is the marginal significance level of that test statistic calculated from the Monte Carlo simulations described above. The marginal significance levels indicate what proportion of the distribution under the hypothesis that the series has a unit root is more extreme than the test statistic. If this number is small it indicates that the test statistic falls in the tail of the distribution and, thus, that it is unlikely the statistic comes from that distribution. Thus a marginal significance level less than 0.05 indicates rejection of the hypothesis that the variable has a unit root at the $5 \%$ level. As we can see from the results in Table 2, there is some support for the view that both the levels of inflation and interest rates contain stochastic trends. In no case do we reject the null hypothesis of a unit root.

We have also conducted unit root tests using Augmented Dickey-Fuller (ADF) tests described by Said and Dickey (1984) in which lags of $\Delta Y$ are included in equation (2). However, these tests suffer from extremely low power (even lower than that of the tests reported) and for this reason are 
not reported here. Nonetheless, the results using these ADF statistics support the findings of Table 2: in no case do we find a rejection of the null hypothesis that inflation and the note rate have unit roots.

Table 2: Unit Root Tests for $\pi_{t}$ and $i_{t}$

\begin{tabular}{|c|c|c|c|c|c|c|}
\hline \multirow[b]{2}{*}{ Sample period } & \multicolumn{3}{|c|}{ Test statistics for $\pi_{t}$} & \multicolumn{3}{|c|}{ Test statistic for $i_{t}$} \\
\hline & DF & $Z_{t}$ & $Z_{a}$ & DF & $Z_{t}$ & $Z_{a}$ \\
\hline 1962 III-1993 IV & $\begin{array}{l}-4.57 \\
(0.57)\end{array}$ & $\begin{array}{l}-4.31 \\
(0.59)\end{array}$ & $\begin{array}{r}-30.55 \\
(0.60)\end{array}$ & $\begin{array}{l}-1.58 \\
(0.74)\end{array}$ & $\begin{array}{l}-1.82 \\
(0.68)\end{array}$ & $\begin{array}{l}-6.23 \\
(0.68)\end{array}$ \\
\hline 1962 III-1979 III & $\begin{array}{l}3.37 \\
(0.49)\end{array}$ & $\frac{-3.14}{(0.50)}$ & $(0.51)$ & $\begin{array}{l}0.79 \\
(0.76)\end{array}$ & $(0.57)$ & $\begin{array}{l}-3.11 \\
(0.43)\end{array}$ \\
\hline 1979 IV-1993 IV & $\begin{array}{l}-3.15 \\
(0.75)\end{array}$ & $\begin{array}{l}-3.02 \\
(0.74)\end{array}$ & $\begin{array}{r}-16.07 \\
(0.71)\end{array}$ & $\begin{array}{l}-1.11 \\
(0.73)\end{array}$ & $\begin{array}{l}-1.52 \\
(0.55)\end{array}$ & $\begin{array}{l}-6.04 \\
(0.35)\end{array}$ \\
\hline
\end{tabular}

Note: The number in parentheses is the marginal significance level of the test statistic calculated from Monte Carlo simulations under the null hypothesis of a unit root.

\section{TESTING FOR LONG-RUN AND SHORT-RUN FISHER EFFECTS}

As Section II has established, the presence of unit roots in the data allows the possibility that there is a long run cointegrating relationship between the two variables, that is, a long-run Fisher effect. Additionally, the presence of a long-run Fisher effect does not rule out the possibility of there also being a short-run Fisher effect.

\section{III (a) The Long-Run Fisher Effect}

Engle and Granger (1987) have demonstrated the linkage between the presence of common stochastic trends and the concept of cointegration. If $\pi_{t}$ and $i_{t}$ are both integrated of order 1 (denoted by saying that they are I(1)) then they are said to be cointegrated of order 1,1 (denoted by $\mathrm{CI}(1,1))$ if a linear combination of them is integrated of order zero. In other words $\pi$, and $i$, are $\mathrm{CI}(1,1)$, if they are both $\mathrm{I}(1)$ and if $\eta_{f}$ is $\mathrm{I}(0)$ in the following so-called cointegrating regression which is the same as the forecasting equation (1):

$$
\pi_{t}=\alpha+\beta i_{t}+\eta_{t}
$$


Engle and Granger then show that a test for cointegration can be done by estimating the cointegrating regression above using ordinary least squares (unless $\beta$ is assumed to be known) and then conducting unit root tests for the regression residual $\eta_{t}$. In other words, the cointegration of $\pi_{t}$ and $i_{t}$, which is what we mean by a long-run Fisher effect, implies that a linear combination of these variables is stationary.

In this paper we consider two sets of cointegration tests. The first set tests for a unit root in $\pi_{t}-\hat{\beta} i_{t}$. The second set conducts unit root tests for $\pi_{t}-i_{t}$ and assumes that $\beta=1$ in the cointegrating regression. These latter tests can be characterised as testing for a full Fisher effect in which inflation and interest rates move one-for-one in the long run.

Another way of looking at the second set of tests is to recognise that they are tests for unit roots in the ex-ante real interest rate under the assumption of rational expectations. This can be demonstrated as follows. The ex-ante real interest rate for a one-period bond $\left(r r_{t}\right)$ is defined as:

$$
r r_{t}=i_{t}-E_{t}\left[\pi_{t}\right]
$$

where $E_{t}[\cdot]$ denotes the expectation taken at time $t$. By subtracting the forecast error of inflation, $\varepsilon_{1}=\pi_{1}-E_{1}\left[\pi_{1}\right]$, from both sides and multiplying both sides by -1 , we see that $\pi_{t}-i_{1}$ can be written:

$$
\pi_{t}-i_{t}=\varepsilon_{t}-r r_{t}
$$

Since under rational expectations the forecast error of inflation $\varepsilon_{\imath}$ must be unforecastable given any information known at time $t, \varepsilon_{t}$ will be $\mathrm{I}(0)$. Hence, $\pi_{t}-i_{t}$ can only be $\mathrm{I}(1)$ if $r r_{t}$ is also $\mathrm{I}(1)$. Testing for a unit root in $\pi_{t}-i_{t}$ is thus equivalent to testing for a unit root in the ex-ante real rate, $r r_{t}$. Looking at the second set of cointegration tests in this light indicates that the full long-run Fisher effect can be interpreted as the hypothesis that the ex-ante real rate is stationary.

\section{III (a) (i) The Problem of Power}

A well-known problem in the time-series literature is that tests for cointegration may have very low power. That is, the ability to distinguish between the two alternatives of cointegration and no cointegration is very low. This problem is particularly severe in our analysis of Australian data because, in contrast to many other countries, the CPI data are only available quarterly rather than monthly. Unfortunately, there is little that can be done to overcome this problem. This conjecture is 
borne out by power calculations based upon Monte Carlo methods reported in Table A2. The power of the two-step Engle Granger method of testing for cointegration never rises much above $50 \%$, indeed, the power is frequently around $10 \%$.

Kremers, Ericsson and Dolado (1992) argue that tests on the significance of the coefficient on the error correction term in error correction models may have much greater power than the Engle Granger method. Following this we estimated two error correction models of the following form with the change in inflation and the change in the note rate as the dependent variables:

$$
\begin{aligned}
& \Delta \pi_{t}=k+A_{11}(L) \Delta \pi_{t-1}+A_{12}(L) \Delta i_{t-1}+\gamma\left(\pi_{t-1}-\beta i_{t-1}\right)+\varepsilon_{t t} \\
& \Delta i_{t}=k+A_{21}(L) \Delta \pi_{t-1}+A_{22}(L) \Delta i_{t-1}-\delta\left(\pi_{t-1}-\beta i_{t-1}\right)+\varepsilon_{2 t}
\end{aligned}
$$

Cointegration implies that the coefficients on the error correction terms, $\gamma$ and $\delta$, are less than zero and so the test for cointegration is a one-sided test for the statistical significance of these coefficients on the error correction terms. To test for the full long-run Fisher effect we run the same regressions imposing $\beta=1$ and conduct the same test for the significance of the $\gamma$ and $\delta$ coefficients.

\section{III (b) Cointegration Tests}

Table 3 contains the results of these tests. To determine which lags of $\Delta \pi$, and $\Delta i$, should be included in regressions the equations are estimated first with eight lags of $\Delta \pi$, and $\Delta i$, and then individual lags are deleted sequentially according to which one is least significant if their coefficients are not significant at the $5 \%$ level. ${ }^{7}$

The first number in the column is the t-statistic on the $\gamma$ and $\delta$ coefficients while the number in parentheses underneath is the marginal significance level of that test statistic generated by Monte Carlo simulations. The Monte Carlo experiments used the procedures outlined in Section III.i.i and the data generating process for the $\pi_{t}$ and $i_{t}$ variables was obtained from ARIMA models in first differenced form (i.e. assuming unit roots).

All the t-statistics in Table 3 are of the correct negative sign. Note that, as demonstrated by Kremers, Ericsson and Dolado (1992), under the null hypothesis of no cointegration, these coefficients have much less negative bias than Dickey-Fuller t-statistics. Hence the fact that their 
estimated values here have the correct sign is encouraging for the view that inflation and short-term interest rates are cointegrated. We also find statistically significant evidence for the stationarity of $e x$ post real interest rates.

Table 3: Cointegration Tests

\begin{tabular}{|c|c|c|c|c|}
\hline \multirow[b]{2}{*}{ Sample period } & \multicolumn{2}{|c|}{$\begin{array}{l}\text { Test statistics for } \\
\text { unit root in } \pi_{t}-\hat{\beta} i_{t}\end{array}$} & \multicolumn{2}{|c|}{$\begin{array}{l}\text { Test statistic for } \\
\text { unit root in } \pi_{t}-i_{t}\end{array}$} \\
\hline & $\gamma$ & $\delta$ & $\gamma$ & $\delta$ \\
\hline 1962 III-1993 IV & $\begin{array}{l}-1.68 \\
(0.92)\end{array}$ & $\begin{array}{l}-2.27 \\
(0.41)\end{array}$ & $\begin{array}{l}-0.57 \\
(0.93)\end{array}$ & $\begin{array}{l}-2.70 \\
(0.05)\end{array}$ \\
\hline $1962 \mathrm{III}-1979 \mathrm{III}$ & $\begin{array}{l}-1.08 \\
(0.91)\end{array}$ & $(0.04)$ & $\begin{array}{l}-1.50 \\
(0.68)\end{array}$ & $\begin{array}{l}-4.53 \\
(0.00)\end{array}$ \\
\hline 1979 IV-1993 IV & $\begin{array}{l}-3.68 \\
(0.45)\end{array}$ & $\begin{array}{l}-2.04 \\
(0.40)\end{array}$ & $\begin{array}{l}-1.19 \\
(0.45)\end{array}$ & $\begin{array}{l}-2.23 \\
(0.18)\end{array}$ \\
\hline
\end{tabular}

Note: The number in parentheses is the marginal significance level of the test statistic calculated from Monte Carlo simulations under the null hypothesis of a unit root and no cointegration.

We see a strong rejection of the null of no cointegration when $\beta=1$ with a marginal significance level less than 0.01 for the pre-1979 sample period when $\Delta i_{t}$ is the dependent variable. We also see that when $\Delta i$ is the dependent variable in the full sample test where $\beta=1$, the t-statistic on $\delta$ has a marginal significance level just slightly above 0.05 , indicating a rejection near the $5 \%$ level.

Power calculations presented in Appendix A support the Kremers, Ericsson and Dolado (1992) position that tests for cointegration in error correction models have more power. The power of these tests is generally greater than the corresponding Engle-Granger tests. However, in a number of cases in Table A3, specifically in tests on $\gamma$, the power is below 5\%. The reason for this is that under the alternative hypothesis of cointegration the distribution of these test statistics has a positive bias; that is, the distribution is perversely shifted towards less negative values with cointegration. Normally one would expect to find more negative values of the test statistic with cointegration than without, however, we find less negative test statistics when there is cointegration. Thus, using the one-sided test we construct, there is virtually no chance of rejecting the null of no cointegration regardless of 
the true situation. Nonetheless, given the very low test statistics found in Table 3 , the results are quite consistent with the series being cointegrated, contrary to the impression that might be given from an examination of Table 3 alone.

Given that the power of the cointegration tests in Table 3 is low as indicated in Appendix A, the fact that we do find several significant rejections of the null of no cointegration when $\beta=1$ suggests that the data are generally supportive of a long-run Fisher effect in Australia. Indeed, any reasonable model of the macro economy would surely suggest that real interest rates have meanreverting tendencies which make them stationary, thus yielding a long-run Fisher relationship. The evidence here is consistent with this view.

\section{III (c) Short-Run Fisher Effects}

The view that there is a long-run Fisher effect in Australia tells us that when the interest rate is higher for a long period of time, then the expected inflation rate will also tend to be high. A short-run Fisher effect, on the other hand, indicates that a change in the interest rate is associated with an immediate change in the expected inflation rate. In other words, we should expect to find a significant positive $\beta$ coefficient in the following regression equation.

$$
E_{t}\left[\pi_{t}\right]-E_{t}\left[\pi_{t-1}\right]=\alpha+\beta\left(i_{t}-i_{t-1}\right)+u_{t}
$$

Because this equation is not estimable, we need to substitute for expected inflation by recognising that $\pi_{t}=E_{t}\left[\pi_{t}\right]+\varepsilon_{t}$, where $\varepsilon_{t}$ is orthogonal to any information available at time $t$ under rational expectations. This substitution results in,

$$
\Delta \pi_{t}=\alpha+\beta \Delta i_{t}+\eta_{t}
$$

where,

$$
\eta_{t}=u_{t}+\varepsilon_{t}-\varepsilon_{t-1}
$$

The presence of $\varepsilon_{t-1}$ in the error term means that the error term can be correlated with the explanatory variable $\Delta i_{t}$ in (10) since rational expectations do not rule out a correlation between $\varepsilon_{t-1}$ and information known at time $t$, such as $\Delta i_{t}$. Consistent estimates are obtained here by using the two-step two-stage least squares procedure outlined in Cumby, Huizinga and Obstfeld (1983) ${ }^{8}$ where the instruments contain information only known at time $t-1.9$ Because real interest rates are 
stationary, one natural way to choose these instruments is by estimating error correction models of the type described by Engle and Granger (1987) in which the variables do not contain information known after time $t-1$, and then choose the significant variables from these models as instruments.

The results from estimating the regression equation above for the different sample periods (starting with 1964 IV because of lagged instruments) are found in Table 4. In assessing the statistical significance of the $t$-statistics on $\beta$, we again conduct Monte Carlo simulations to provide the marginal significance level of the t-statistic reported in the last column of Table 4 . The data generating process is specified to be one in which the $\Delta \pi_{t}$ and $\Delta i_{t}$ variables are generated from error correction models in which the current and past values of $\Delta i$ do not appear in the $\Delta \pi$, equation, since under the null $\Delta i_{t}$ has no forecasting ability for $\Delta \pi_{t} \cdot{ }^{10}$

Table 4: Tests for Short-Run Fisher Effects $\Delta \pi_{t}=\alpha+\beta \Delta i_{t}+\eta_{t}$

\begin{tabular}{|c|c|c|c|c|c|}
\hline Sample period & $\alpha$ & $\beta$ & $S E$ & $\begin{array}{l}\text { t-statistic } \\
\text { for } \beta=0\end{array}$ & $\begin{array}{c}\text { Marginal } \\
\text { significance level } \\
\text { for t-statistic }\end{array}$ \\
\hline 1964 IV-1993 IV & $\begin{array}{l}-0.00 \\
(0.20)\end{array}$ & $\begin{array}{c}0.06 \\
(0.67)\end{array}$ & 3.38 & 0.08 & 0.92 \\
\hline 1964 IV -1979 III & $\begin{array}{l}0.21 \\
(0.33)\end{array}$ & $\begin{array}{l}0.46 \\
(1.29)\end{array}$ & 3.86 & -0.35 & 0.77 \\
\hline 1979 IV-1993 IV & $\begin{array}{l}-0.12 \\
(0.25)\end{array}$ & $\begin{array}{c}0.18 \\
(0.74)\end{array}$ & 2.83 & 0.25 & 0.74 \\
\hline
\end{tabular}

Note: Standard errors in parentheses.

The Table 4 results indicate that the $t$-statistics on the $\beta$ coefficients are well less than one, and the $\beta$ coefficient with the largest $t$-statistic even has the wrong sign. ${ }^{11}$ Therefore, there is absolutely no evidence for the presence of a short-run Fisher effect in the regression results presented in Table 4.

\section{INTERPRETING INFLATION FORECASTING EQUATIONS}

The conclusion from the preceding empirical analysis is that it is reasonable to assume that there is a long-run Fisher effect in Australia but not a short-run Fisher effect. This characterisation of 
the inflation and interest rate data along with the assumption of rational expectations can be used to provide a straightforward interpretation of when we will be likely to see estimated $\beta$ coefficients substantially above zero in the inflation forecasting equation (1). As in Mishkin (1990), we can derive an expression for the coefficient $\beta$ in the inflation forecasting equation (1) by writing down the standard formula for the projection coefficient $\beta$, while recognising that the covariance of the inflation forecast error with the real interest rate, $r r_{t}$, equals zero given rational expectations. The resulting formula for the predicted value of $\beta$ is:

$$
\beta=\frac{\tilde{\sigma}^{2}+\rho \tilde{\sigma}}{1+\tilde{\sigma}^{2}+2 \rho \tilde{\sigma}}
$$

where,

$\tilde{\sigma}=\sigma\left[E_{t}\left(\pi_{t}\right)\right] / \sigma\left[r r_{t}\right]=$ the ratio of the unconditional standard deviation of the expected inflation rate to the unconditional standard deviation of the real interest rate.

$\rho=$ the unconditional correlation coefficient between the expected inflation rate, $E_{t}\left(\pi_{t}\right)$, and the one-period real interest rate, $r r_{i}$.

The equation above indicates that $\beta$ is determined by how variable the level of expected inflation is relative to the variability of the real interest rate (represented by $\tilde{\sigma}$, the ratio of the standard deviations of $E_{t}\left(\pi_{t}\right)$ and $\left.r r_{1}\right)$, as well as by the correlation of the expected inflation rate with the real interest rate $(\rho)$. Figure 2 shows how $\beta$ varies with $\tilde{\sigma}$ and $\rho$.

As we can see in Figure 2, when the variability of the level of inflation is greater than the variability of the real interest rate, so that $\tilde{\sigma}$ is above 1.0 , the $\beta$ coefficient will always exceed 0.5 and will increase as $\tilde{\sigma}$ increases. If inflation has a unit root and thus does not have a stationary stochastic process, as is consistent with the empirical evidence in this paper, then its second moment is not well defined and the standard deviation of the inflation level will grow with the sample size. On the other hand, the existence of a long-run Fisher effect implies that even if inflation and interest rates have unit roots, the real interest rate has a stationary stochastic process and will have a well defined standard deviation that does not grow with the sample size. Hence when we are in a fairly long sample period 
in which inflation and interest rates have unit roots, the existence of a long-run Fisher effect means that $\tilde{\sigma}$ will be likely to exceed one and produce a value of $\beta$ substantially above zero.

Figure 2: How $\beta$ Varies With $\tilde{\sigma}$ and $\rho$

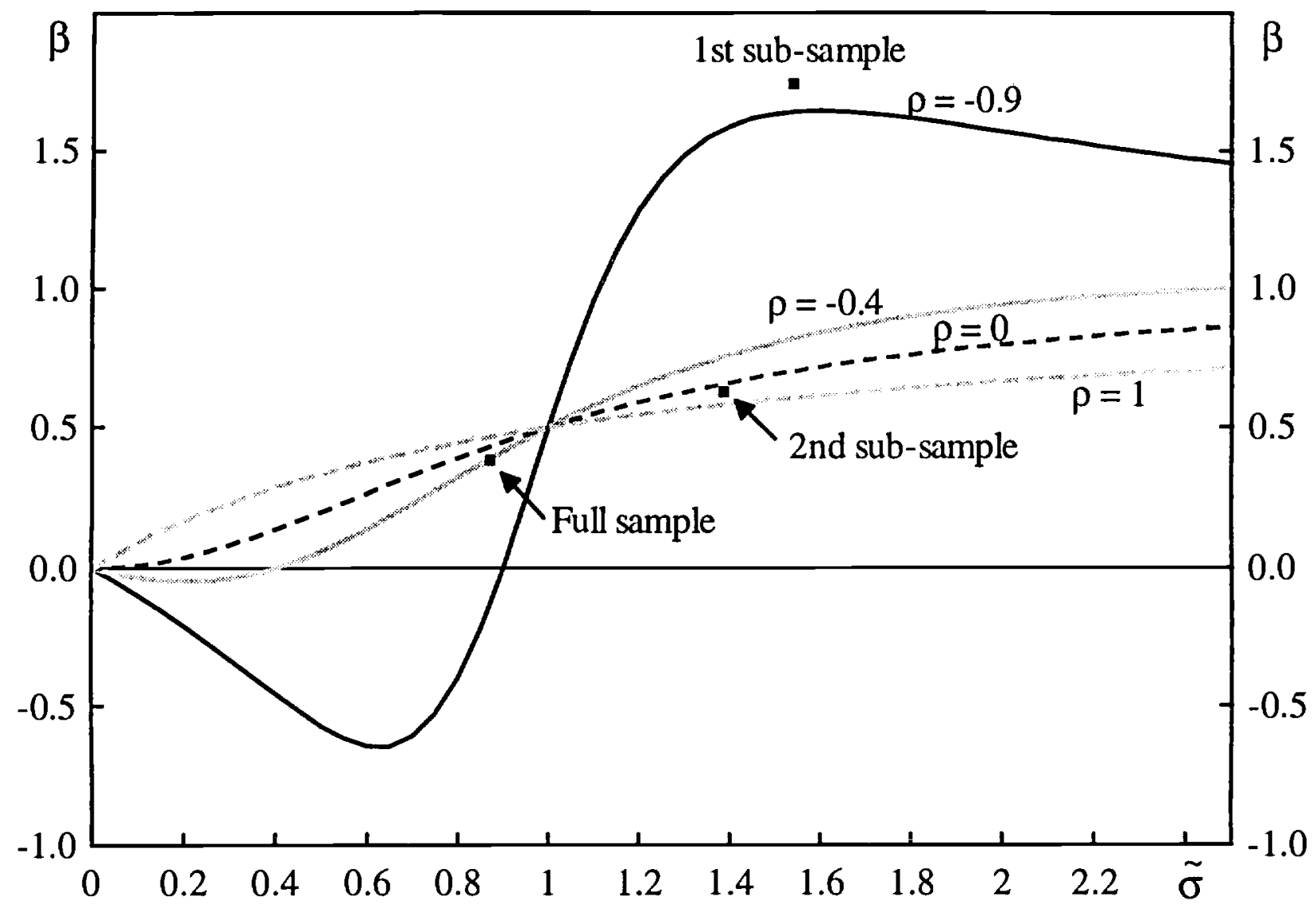

The above interpretation helps explain why we see the strong correlation between interest rates and future inflation that we found for both pre and post 1979 sample periods in Table 1. To see this more clearly, we can calculate estimated values of $\tilde{\sigma}$ and $\rho$. We do this by using the procedure outlined in Mishkin (1981), where estimates of the real rate, $r r_{t}$, are obtained from fitted values of regressions of the ex-post real rate on past inflation changes and past interest rates. ${ }^{12}$ Then the estimated expected inflation is calculated from the following definitional relationship,

$$
E_{t}\left(\pi_{t}\right)=i_{i}-r r_{t}
$$

Finally estimates of $\sigma\left[E_{t}\left(\pi_{t}\right)\right], \sigma\left[r r_{t}\right]$, and $\rho$ are calculated from the estimated $E_{t}\left(\pi_{t}\right)$ and $r r_{t}$. 
Figure 3: Estimates of Expected Inflation and Real Interest Rates

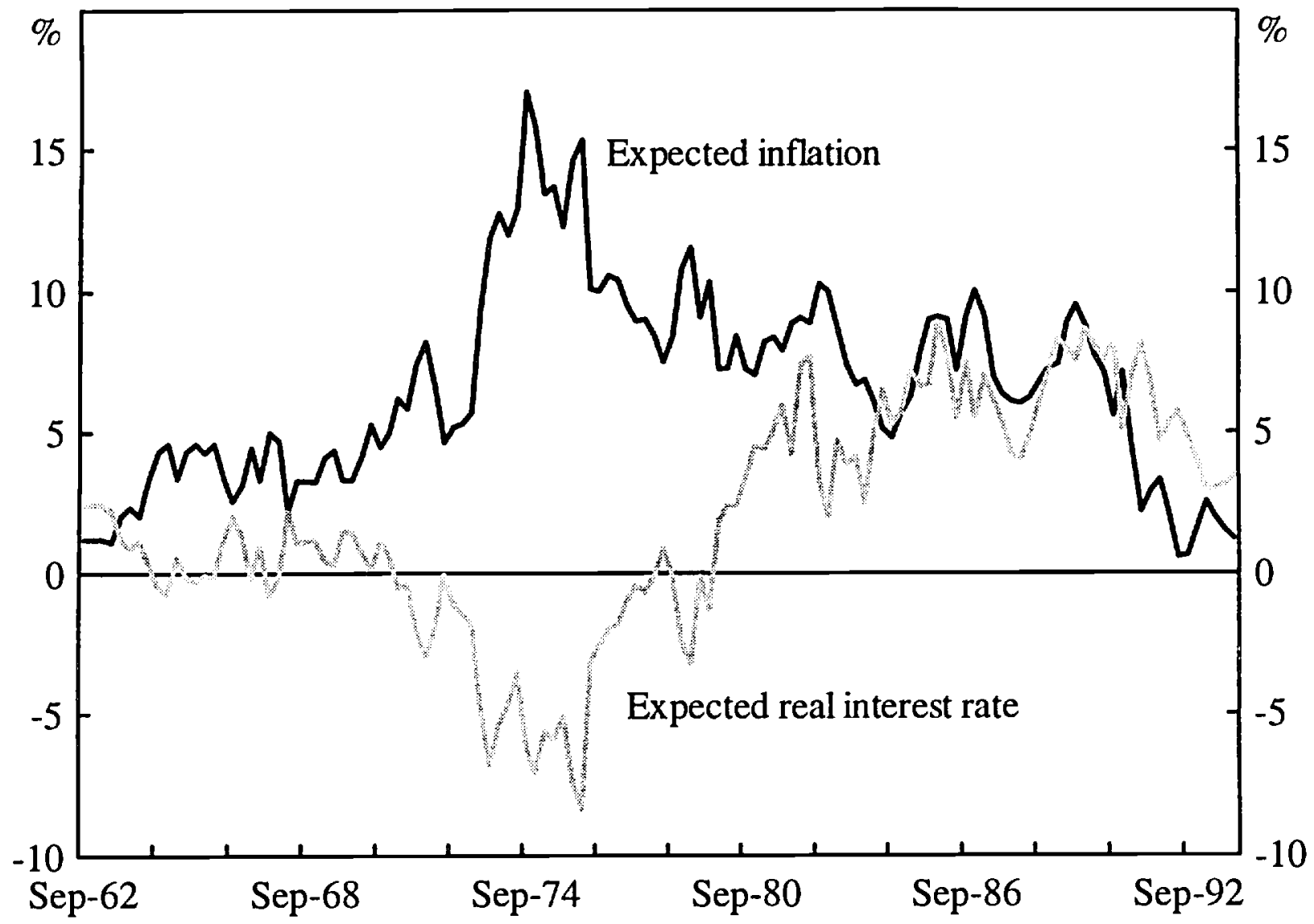

Figure 3 shows the resulting estimates of expected inflation and real interest rates, $E_{1}\left(\pi_{t}\right)$ and $r r_{t}$ respectively, while the $\tilde{\sigma}$ estimates for each of the sample periods are shown in Figure 2. As we can see from Figure 3, the variability of expected inflation is greater than that of the real interest rate in the pre 1979 period, resulting in a pre $1979 \tilde{\sigma}$ of 1.5. Also as is visible in Figure 3, expected inflation and the real rate are highly negatively correlated with a correlation coefficient of -0.9 . As Figure 2 indicates, the predicted $\beta$ using these values of $\tilde{\sigma}$ and $\rho$ for the pre 1979 sample period is substantially greater than one, which is what we found in Table $4 .{ }^{13}$ For the post 1979 sample, expected inflation continues to be more variable than the real rate leading to an estimate of $\tilde{\sigma}$ of 1.4 , while there is little correlation of expected inflation and real rates, $\rho=0.2$. The slightly lower $\tilde{\sigma}$ and more positive $\rho$ leads to a predicted $\beta$ which is lower in the post 1979 sample than in the pre 1979 sample, although it is still greater than 0.5 because $\tilde{\sigma}$ is greater than one. Our analysis thus explains why the estimated $\beta$ coefficient in Table 1 falls in going from the pre 1979 to the post 1979 period. 
Figure 3 also shows that estimated real interest rate had a dramatic upward shift after 1979, a result which has also been found in other OECD countries. ${ }^{14}$ This shift in the real interest rate causes the standard deviation of the real rate to be higher for the full sample period than it is for either of the sub-periods, thus leading to a $\tilde{\sigma}$ for the whole sample of 0.9 . The $\tilde{\sigma}$ less than one means that $\beta$ should drop below 0.5 and this is again what is found in Table 1 . We see that the pattern of estimated $\beta$ found in Table 1 is exactly what our model predicts.

\section{CONCLUSION}

This paper has examined the Fisher effect in Australia. Recognition that the level of inflation and interest rates may contain stochastic trends suggests that the correlation between expected inflation and short-term nominal interest rates in Australia is the result of a long-run Fisher effect in which inflation and interest rates trend together in the long run rather than a short-run Fisher effect in which changes in short-term interest rates reflect changes in expected inflation. These findings have important implications for policy makers. They indicate that the level of short-term interest rates can be an inappropriate guide for monetary policy because a high interest rate that has persisted for some time is an indication that expected inflation is high. Hence the high level of the interest rate is not an indicator that monetary policy is tight, indeed it might indicate the reverse. This suggests that looking solely at the level of short-term interest rates can produce a misleading picture of the stance of monetary policy. Fixation on the level of short-term interest rates either by the public or the central bank can thus lead to inappropriate policies. On the other hand the evidence that a short-run Fisher effect does not exist in Australia, suggests that short-run changes in the short-term interest rate reflect changes in the real interest rate rather than expected inflation. Thus changes in short-term interest rates can reflect the stance of monetary policy. 


\section{APPENDIX A: POWER CALCULATIONS}

The power calculations found in Table Al are obtained from Monte Carlo simulations using the same procedure that was described in Section 3.1.1, however, the data generating process is estimated from ARIMA models estimated in levels rather than first differences, that is, ARMA models. The power calculation for each test statistic in the table is the probability obtained from this Monte Carlo simulation of rejecting the null of a unit root given the alternative of no unit root using the size-corrected $5 \%$ critical value for the test statistic.

Table A1: Power of Integration Test Statistics in Table 2

\begin{tabular}{|l||ccc|ccc|}
\hline \multirow{2}{*}{ Sample period } & \multicolumn{3}{c|}{ Test statistics for $\pi_{t}$} & \multicolumn{3}{c|}{ Test statistic for $i_{t}$} \\
\cline { 2 - 7 } 1962 III-1993 IV & DF & $Z_{t}$ & $Z_{a}$ & DF & $Z_{t}$ & $Z_{a}$ \\
\hline 1962 m-1979 III & 0.093 & 0.094 & 0.090 & 0.053 & 0.032 & 0.029 \\
1979 IV-1993 IV & 0.095 & 0.098 & 0.107 & 0.162 & 0.166 & 0.178 \\
\hline
\end{tabular}

Tables A2 and A3 contains the power calculations for test statistics from the Engle Granger two step method and the ECM equations reported in Table 3 using similar Monte Carlo simulations to those used in Table Al. The data generating process for the cointegration tests for a unit root in $\pi_{t}-\hat{\beta}_{t}$ is an error correction model in which the error correction term is $\pi_{t}-\hat{\beta} i_{t}$. Similarly, the data generating process used for the tests of a unit root in $\pi_{t}-i_{t}$ is an error correction model in which the error correction term is $\pi_{t}-i_{t}$. The test statistics in Table A2 are the same as those reported in Table 2 and Table A1, that is, Dickey-Fuller t-tests and Phillips $Z_{t}$ and $Z_{\alpha}$ tests. 
Table A2: Power of Engle Granger Co-Integration Test Statistics

\begin{tabular}{|l||ccc|ccc|}
\hline \multirow{2}{*}{} & \multicolumn{3}{|c|}{$\begin{array}{c}\text { Test statistics for } \\
\text { unit root in } \pi_{t}-\hat{\beta} i_{t}\end{array}$} & \multicolumn{3}{c|}{$\begin{array}{c}\text { Test statistic for } \\
\text { unit root in } \pi_{t}-i_{t}\end{array}$} \\
\cline { 2 - 8 } Sample period & DF & $Z_{t}$ & $Z_{a}$ & DF & $Z_{t}$ & $Z_{a}$ \\
\hline \hline $1962 \mathrm{III}-1993 \mathrm{IV}$ & 0.076 & 0.086 & 0.096 & 0.188 & 0.192 & 0.196 \\
$1962 \mathrm{III}-1979 \mathrm{II}$ & 0.449 & 0.503 & 0.606 & 0.461 & 0.507 & 0.573 \\
$1979 \mathrm{IV}-1993 \mathrm{IV}$ & 0.030 & 0.027 & 0.021 & 0.417 & 0.363 & 0.275 \\
\hline
\end{tabular}

Table A3: Power of ECM Co-Integration Tests in Table 3

\begin{tabular}{|l||cc|cc|}
\hline & \multicolumn{2}{|c|}{$\begin{array}{c}\text { Test statistics for } \\
\text { unit root in } \pi_{t}-\hat{\beta} i_{t}\end{array}$} & \multicolumn{2}{|c|}{$\begin{array}{c}\text { Test statistic for } \\
\text { unit root in } \pi_{t}-i_{t}\end{array}$} \\
\cline { 2 - 5 } Sample period & $\gamma$ & $\delta$ & $\gamma$ & $\delta$ \\
\hline \hline $1962 \mathrm{III}-1993 \mathrm{IV}$ & 0.012 & 0.081 & 0.012 & 0.634 \\
$1962 \mathrm{III}-1979 \mathrm{III}$ & 0.034 & 0.358 & 0.072 & 0.750 \\
$1979 \mathrm{IV}-1993 \mathrm{IV}$ & 0.019 & 0.284 & 0.690 & 0.523 \\
\hline
\end{tabular}

In most cases the power of tests in Table $A 1, A 2$ and $A 3$ are very low. This stems from both the low power of the tests themselves and the low number of observations we have to work with. 


\section{APPENDIX B: DATA}

The analysis makes use of quarterly data on inflation rates and thirteen week Treasury note interest rates for the period from the third quarter of 1962 until the fourth quarter of 1993. The sample starts with the third quarter of 1962 because this is the first date that data on Treasury notes are consistently available. The CPI data are an average over the quarter so the Treasury note interest rate data are also averaged over the quarter. The Treasury note data were obtained from the Reserve Bank of Australia Bulletin for data covering 1962 III to 1982 II. Over this period the monthly observations reported in the Bulletin are averaged. ${ }^{15}$ Thereafter internal sources are used to construct the quarterly averages using daily data. The inflation data are the headline CPI rate adjusted for Medibank and the introduction of the Medicare levy. ${ }^{16}$ The timing of the variables is as follows. For a first quarter observation the interest rate is the average of the Treasury note interest rates over the quarter, while the inflation rate is calculated from the first and second quarter CPI data. 


\section{REFERENCES}

Carmichael, J. and P.W. Stebbing (1983), "Fisher's Paradox and the Theory of Interest", American Economic Review, 73, pp. 619-630.

Clarida, R.H. and B.M. Friedman (1984), "The Behaviour of U.S. Short-Term Interest Rates Since October 1979", Journal of Finance, 39, pp. 671-682.

Cumby, R.E. and F.S. Mishkin (1986), "The International Linkage of Real Interest Rates: The European-U.S. Connection", Journal of International Money and Finance, 5, pp. 5-23.

Cumby, R.J., J. Huizinga and M. Obstfeld (1983), "Two-Step, Two-Stage Least Squares Estimation in Model with Rational Expectations", Journal of Econometrics, 21, pp. 333-55.

Dickey, D.A. and W.A. Fuller (1979), "Distribution of the Estimators for Autoregressive Time Series with a Unit Root," Journal of the American Statistical Association, 74, pp. 427-31.

Dickey, D.A. and W.A. Fuller (1981), "Likelihood Ratio Statistics for Autoregressive Time Series with a Unit Root", Econometrica, 49, pp. 1057-72.

DeJong, D.N., J.C. Nankervis, N.E. Savin and C.H. Whiteman (1988), "Integration Versus Trend-Stationarity in Macroeconomic Time Series", Department of Economics, University of Iowa, Working Paper No. 88-27a.

Engle, R.F. and C.W. Granger (1987), "Co-Integration and Error Correction: Representation, Estimation and Testing", Econometrica, 55, pp. 251-76.

Fama, E.F. (1975), "Short Term Interest Rates as Predictors of Inflation", American Economic Review, 65, pp. 269-82.

Fama, E.F. and M.R. Gibbons (1982), "Inflation, Real Returns and Capital Investment", Journal of Monetary Economics, 9, pp. 297-324.

Granger, C.W. and P. Newbold (1974), "Spurious Regression in Econometrics", Journal of Econometrics, 2, pp. 111-120.

Hansen, L.P. (1982), "Large Sample Properties of Generalised Method of Moments Estimators," Econometrica, 50, pp. 1029-54. 
Huizinga, J. and F.S. Mishkin (1984), "Inflation and Real Interest Rates on Assets with Different Risk Characteristics", Journal of Finance, 39, pp. 699-712.

Kremers, J.J.M., N.R. Ericsson and J.J. Dolado (1992), "The Power of Cointegration Tests", Oxford Bulletin of Economics and Statistics, 54, pp. 325-348.

Mishkin, F.S. (1981), "The Real Rate of Interest: An Empirical Investigation", The Cost and Consequences of Inflation, Carnegie-Rochester Conference Series on Public Policy, 15, pp. 151-200. Mishkin, F.S. (1984), "The Real Interest Rate: A Multi-Country Empirical Study", Canadian Journal of Economics, 17, pp. 283-311.

Mishkin, F.S. (1988), "Understanding Real Interest Rates", American Journal of Agricultural Economics, 70, pp. 1064-72.

Mishkin, F.S. (1990), "What Does the Term Structure of Interest Rates Tell Us About Future Inflation?", Journal of Monetary Economics, 25, pp. 77-95.

Mishkin, F.S. (1992), "Is the Fisher Effect for Real?", Journal of Monetary Economics, 30, pp. 195215.

Nelson, C.R. and G.W. Schwert (1977), "Short-Term Interest Rates as Predictors of Inflation: On Testing the Hypothesis that the Real Rate of Interest is Constant", American Economic Review, 67, pp. 478-86.

Newey, W. and K. West (1988), "A Simple, Positive Definite, Heteroskedasticity and Autocorrelation Consistent Covariance Matrix", Econometrica, 55, pp. 703-708.

Perron, P. (1990), "Testing for a Unit Root in a Time Series with a Changing Mean", Journal of Business and Economic Statistics, 8, pp. 153-162.

Phillips, P.C.B. (1986), "Understanding Spurious Regressions in Econometrics", Journal of Econometrics, 33, pp. 311-40.

Phillips, P.C.B. (1987), "Time Series Regression with a Unit Root", Econometrica, 55, pp. 277-301. Schwert, G.W. (1987), "Effects of Model Specification on Tests for Unit Roots in Macroeconomic Data", Journal of Monetary Economics, 20, pp. 73-103. 
Said, S.E. and D.A. Dickey (1984), "Testing for Unit Roots in Autoregressive-Moving Average Models of Unknown Order", Biometrika, 71, pp. 599-608.

White, H. (1980), "A Heteroskedasticity-Consistent Covariance Matrix Estimator and Direct tests for Heteroskedasticity", Econometrica, 48, pp. 817-38.

\section{ENDNOTES:}

1 See, for example, Fama (1975), Nelson and Schwert (1977), Mishkin (1981, 1984, 1988), Fama and Gibbons (1982).

2 The deregulation of financial markets provides an a priori reason for choosing the breakpoint at 1979 III. Figure 1 also suggests that a break occurred at this time. Unfortunately, econometric testing for whether the break occurred somewhat earlier or later does not have the power to distinguish between these alternatives. However, moving the breakpoint by several quarters does not appreciably affect the results in Table 1 or in later tables.

3 This has been forcefully demonstrated by Granger and Newbold (1974) and Phillips (1986) among others.

4 This has been pointed out by Schwert (1987) using Monte Carlo simulations.

5 This is used as the true distribution for the hypothesis that the variables are integrated but not cointegrated with each other.

6 The $Z_{t}$ and $Z_{\alpha}$ test statistics are calculated allowing for 4 non-zero autocovariances in the error term of regression (4).

7 We also used a criterion of significance at the $10 \%$ level as well as a procedure where the longest lags on $\Delta \pi$ and $\Delta i$ were dropped until the last lag was found to be significant; the intervening lags continued to be included in the regression even if they were insignificant. Monte Carlo simulations indicated that these procedures yielded tests with lower power and this is why we used the procedure outlined in the text. However, in general, these procedures led to similar conclusions although marginal significance levels were generally lower than those reported in Table 3.

8 Note that the Newey-West (1987) technique is used to ensure positive-definiteness of the variance-covariance matrix rather than a spectral method as in Cumby, Huizinga and Obstfeld (1983).

9 In the estimation $\eta_{t}$ is assumed to have a MA process of order 1. The order of the MA process is one because the presence of $\varepsilon_{t-1}$ as well as $\varepsilon_{t}$ in the error term of equation (7) means that the autocorrelation at lag one can be non-zero.

10 Note that these error-correction models differ from the ones used to choose the instruments because there is no longer the restriction that the explanatory variables in these models must only contain information available at time $t$ - 1 . Similar Monte Carlo results would be obtained if the data generating processes instead assume that $\pi_{t}$ and $i_{t}$ are stationary in levels or have unit roots but are not cointegrated.

11 A number of instrument sets were tried to improve the regressions. Instruments were chosen on the basis of error correction models similar to equations (8) and (9) with $\beta=1$ imposed. 
Insignificant lags were removed at the $10 \%$ and $5 \%$ levels to provide two sets of instruments. Furthermore, we tried using the same set of instruments for all sample periods, once again at the $10 \%$ and $5 \%$ levels of significance. However, similar results are found using these sets of instruments and with OLS, thus suggesting that the inability to find a short-run Fisher effect does not stem from the procedure used here for choosing instruments. The instruments used in the results reported in Table 4 included the regressors of the ECM which were significant at the 5\% level. They were estimated separately for each sub-period and then amalgamated using dummies to provide instruments for the full sample.

12 The estimates described in the text were generated from OLS regressions in which the ex-post real rate, eprr $r_{t}$, was regressed on $i_{t}$, and on $\pi_{t-1}$ and $\pi_{t-2}$. The estimated values of $\tilde{\sigma}$ and $\rho$ are robust to different specifications of the regression equations.

13 This is consistent with the results of Carmichael and Stebbing (1983).

14 See Cumby and Mishkin (1986).

15 These observations are based upon the average yield of the last tender of the month.

16 The headline CPI which is used to construct the inflation variable suffers from an inappropriate treatment of the housing component and, in addition, includes volatile components such as fuel and energy. As a result we have also looked at results using inflation constructed from an adjusted CPI which, unfortunately, only starts after 1972 because the necessary expenditure breakdown is not available earlier. Nonetheless, we find results very similar to those found with the headline CPI series and so choose to use the headline measure as it is available over a longer time horizon. 